\title{
Early surgical intervention versus watchful waiting and outcomes for asymptomatic severe aortic regurgitation
}

\author{
Christophe de Meester, MS, ${ }^{\mathrm{a}, \mathrm{b}}$ Bernhard L. Gerber, MD, PhD, ${ }^{\mathrm{a}, \mathrm{b}}$ David Vancraeynest, MD, PhD, ${ }^{\mathrm{a}, \mathrm{b}}$ \\ Anne-Catherine Pouleur, MD, PhD, ${ }^{\mathrm{a}, \mathrm{b}}$ Philippe Noirhomme, MD, ${ }^{\mathrm{a}, \mathrm{c}}$ Agnès Pasquet, MD, PhD, ${ }^{\mathrm{a}, \mathrm{b}}$ \\ Gébrine El Khoury, MD, ${ }^{a, c}$ and Jean-Louis Vanoverschelde, $\mathrm{MD}, \mathrm{PhD}^{\mathrm{a}, \mathrm{b}}$
}

\begin{abstract}
Objectives: The management of asymptomatic patients with severe aortic regurgitation remains controversial. Accordingly, the aim of the present study was to assess the long-term outcomes and incidence of cardiac complications among asymptomatic patients with severe aortic regurgitation who underwent operation early, in the absence of any class I or class IIa guideline triggers, or were managed conservatively and eventually underwent operation whenever these triggers appeared.
\end{abstract}

Methods: A total of 160 consecutive asymptomatic patients ( $50 \pm 17$ years) with severe aortic regurgitation were prospectively followed up for a median of 7.2 years. Overall and cardiovascular survivals and the need for repeat aortic regurgitation surgery were evaluated in an "early surgery" group $(n=91)$ and a "conservatively managed" group $(n=69)$.

Results: Ten-year overall $(91 \% \pm 4 \%$ vs $89 \% \pm 5 \%, P=.87)$ and cardiovascular $(96 \% \pm 2 \%$ vs $96 \% \pm 3 \%, P=.79)$ survivals were similar among the early surgery and conservatively managed groups. Conservatively managed patients were further sub-stratified according to the regularity and quality of their follow-up. Patients who were regularly followed up by a certified cardiologist had a better 10-year overall survival than patients undergoing no or a looser follow-up $(95 \% \pm 5 \%$ vs $79 \% \pm 10 \%, P=.045)$. Multivariate Cox proportional hazards analysis identified age $(P=.003)$ and male gender $(P=.024)$ as independent predictors of survival. Early surgical management was not a predictor of outcome $(P=.45)$.

Conclusions: Our results show that the outcome of asymptomatic patients with severe aortic regurgitation is not different between an early surgical and a more conservative strategy, provided that the conservatively managed patients are regularly followed up and timely referred to surgery as soon as operative triggers develop. This suggests that surgery should not be recommended in patients with aortic regurgitation who do not meet current guidelines for intervention. ( $\mathrm{J}$ Thorac Cardiovasc Surg 2015;150:1100-8)

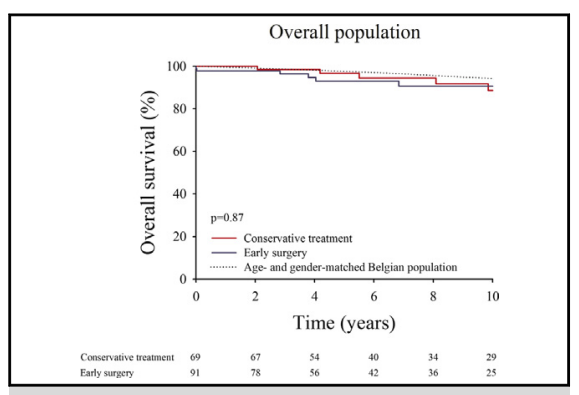

In asymptomatic severe AR, early surgery and a watchful waiting result in similar outcomes.

\section{Central Message}

In asymptomatic severe AR, delaying surgery until the onset of class I/IIa operative triggers is safe, supporting current guidelines.

\section{Perspective}

We compared long-term outcomes in asymptomatic patients with severe AR who underwent operation early or were initially managed conservatively. We found that survival was similar in the 2 groups, although better survival was observed in conservatively managed patients with regular follow-up as opposed to no or a looser follow-up.

See Editorial Commentary page 1108.
From the âole de Recherche Cardiovasculaire, Institut de Recherche Expérimentale et Clinique, Université Catholique de Louvain, Brussels, Belgium; Divisions of ${ }^{\mathrm{b}}$ Cardiology, and ${ }^{\mathrm{c} C a r d i o t h o r a c i c ~ S u r g e r y, ~ C l i n i q u e s ~ U n i v e r s i t a i r e s ~ S a i n t-L u c, ~}$ Brussels, Belgium.

This work was supported by the Fonds National de la Recherche Scientifique, Brussels, Belgium.

Received for publication Feb 1, 2015; revisions received July 1, 2015; accepted for publication July 16, 2015; available ahead of print Aug 19, 2015.

Address for reprints: Jean-Louis Vanoverschelde, MD, PhD, Division of Cardiology, Cliniques Universitaires Saint-Luc, Avenue Hippocrate, 10-2881, B-1200 Brussels, Belgium (E-mail: jean-louis.vanoverschelde@uclouvain.be).

0022-5223/\$36.00

Copyright (c) 2015 by The American Association for Thoracic Surgery

http://dx.doi.org/10.1016/j.jtcvs.2015.07.053
Volume overload from chronic severe aortic regurgitation (AR) is usually well tolerated by the left ventricle so that patients may long remain asymptomatic. The development of symptoms occurs later and most often implies left ventricular (LV) decompensation. Once symptoms have become apparent, mortality in the absence of surgical treatment markedly increases and can be as high as $10 \%$ to $20 \%$ per year. ${ }^{1}$ Because the appearance of symptoms identifies a critical point in the natural history of severe AR, and aortic valve replacement (AVR) not only results in symptomatic relief but also improves $\mathrm{LV}$ function and survival, the 


\author{
Abbreviations and Acronyms \\ ACC = American College of Cardiology \\ AHA $=$ American Heart Association \\ $\mathrm{AR}=$ aortic regurgitation \\ $\mathrm{AV}=$ aortic valve \\ AVR = aortic valve replacement \\ $\mathrm{CI}=$ confidence interval \\ $\mathrm{ESC}=$ European Society of Cardiology \\ $\mathrm{HR}$ = hazard ratio \\ IPW = inverse probability-weighted \\ $\mathrm{LV}=$ left ventricular \\ NYHA $=$ New York Heart Association
}

most recent European Society of Cardiology (ESC) and American Heart Association (AHA)/American College of Cardiology (ACC) guidelines have considered symptomatic severe AR as a class I indication for surgery, regardless of LV systolic function. ${ }^{2,3}$

The optimal timing of surgery in asymptomatic severe AR is more controversial. Although earlier studies have shown that the prognosis of patients with no or minimal symptoms was relatively benign and that surgery could be safely delayed until symptoms develop, ${ }^{1,4}$ recent evidence has accumulated that suggests the opposite. First, large postoperative studies have demonstrated that the presence of heart failure symptoms in the preoperative patient negatively affects postoperative outcomes, suggesting that surgical correction should be performed before the onset of symptoms. ${ }^{5,6}$ Second, with long-standing severe AR, LV dysfunction eventually develops, which increases operative risks. ${ }^{7,8}$ Finally, the development of irreversible myocardial fibrosis in markedly remodeled volume-overloaded LVs is a frequent cause of persisting postoperative LV dysfunction and heart failure, even after successful AVR. ${ }^{9-11}$

Despite these arguments, the 2012 ESC guidelines have been reluctant to propose an early surgical correction for asymptomatic patients with severe $\mathrm{AR}^{3}{ }^{3}$ accepting to consider this only in the presence of LV dysfunction or severe $\mathrm{LV}$ dilatation $(>70 \mathrm{~mm}$ of end-diastolic diameter or $>50 \mathrm{~mm}$ of end-systolic diameter). Although the recent 2014 AHA/ACC guidelines have been somewhat less restrictive, the overall consensus remains that most patients with asymptomatic severe AR should be managed conservatively and referred to surgery only once symptoms, LV dysfunction, or severe LV dilatation have developed, considering that both operative mortality and the ongoing risks of a prosthetic valve outweigh the potential benefit of an early surgical intervention. ${ }^{4}$

In the past, operative mortality after AVR was undoubtedly too high to propose an early surgical correction for asymptomatic patients with severe AR. ${ }^{12}$ However, with the advent of aortic valve $(\mathrm{AV})$ repair, operative mortality and long-term outcomes have improved to such an extent that early surgery has become a plausible option for these patients. ${ }^{13-16}$ Accordingly, the aim of the present study was to assess the long-term outcomes and incidence of cardiac complications among patients with severe AR who underwent operation early, in the absence of any class I or class IIa triggers, or were initially managed conservatively and eventually underwent operation whenever these triggers appeared.

\section{MATERIALS AND METHODS \\ Study Population}

Since the year 2000, all patients with valvular heart disease seen at the Cliniques Universitaires St-Luc are enrolled into a prospective registry in which baseline and follow-up demographics, clinical data, and digital echocardiographic images are collected and stored. Informed consent is obtained from each patient, and the study protocol has been approved by the internal review board of our institution. Between 1995 and 2000, consecutive patients with valvular heart diseases were retrieved from the clinical echocardiographic database. For these patients, approval of the study protocol and waiver of informed consent for retrospective data handling were obtained from the institutional review board.

Between January 1, 1995, and December 31, 2012, 701 consecutive patients were diagnosed with severe AR at our institution. From this initial cohort, we selected only those patients who were in New York Heart Association (NYHA) class I at the time of diagnosis and had no class I or class IIa triggers for surgery, according to the 2014 AHA/ACC and the 2012 ESC guidelines. ${ }^{2,3}$ Among the 285 eligible patients, those aged less than 18 years $(n=12)$ and those who had concomitant severe mitral regurgitation or aortic stenosis $(\mathrm{n}=29)$, a nondilated $\mathrm{LV}$, defined as a LV end-diastolic dimension less than $32 \mathrm{~mm} / \mathrm{m}$ height $(\mathrm{n}=53),{ }^{17}$ prior valve surgery $(n=21)$, a glomerular filtration rate less than $30 \mathrm{~mL} / \mathrm{min}(\mathrm{n}=3)$, or a life expectancy less than 1 year in the absence of $\operatorname{AR}(n=7)$ were secondarily excluded (Figure 1$)$.

\section{Transthoracic and Transesophageal \\ Echocardiography}

Preoperative and intraoperative echocardiographic examinations were performed with commercially available ultrasound systems. All patients underwent a comprehensive examination, including M-mode and 2dimensional echocardiography, and Doppler examinations. All tests were conducted by experienced sonographers. The mechanisms of AR dysfunction were classified in 3 different subtypes, as previously described. ${ }^{18}$ Briefly, type I dysfunction was considered when the dimensions of any components of the aortic root, including the aortic annulus, the sinuses of Valsalva, and the sinotubular junction exceeded the upper limits of published normal values and no other cause of AR was identified. Type 2 dysfunction was considered in the presence of an eccentric AR jet and either a cusp prolapse or a cusp fenestration. Type 3 dysfunction was considered whenever the quality or quantity of the cusp tissue was judged to be poor. Thickened and rigid valves with reduced motion, valves whose leaflet tissue had been destroyed by endocarditis, and severely calcified valves were included in this category.

The severity of AR was ascertained using an integrated approach that included the size of the regurgitant jet in the LV cavity, the proximal regurgitant jet width, the jet deceleration rate, the magnitude of the diastolic flow reversal in descending aorta, the size of the proximal convergence zone, and when available, the regurgitant volume and effective regurgitant orifice area. Severe AR was defined as a grade $3+$ or greater AR. The approach to semiquantification used in the present study is in agreement with prevailing guidelines at the time of examination. LV volumes and LV ejection fraction were calculated by use of the biplane Simpson method. Aortic root dimensions were measured as previously described. ${ }^{17}$ 


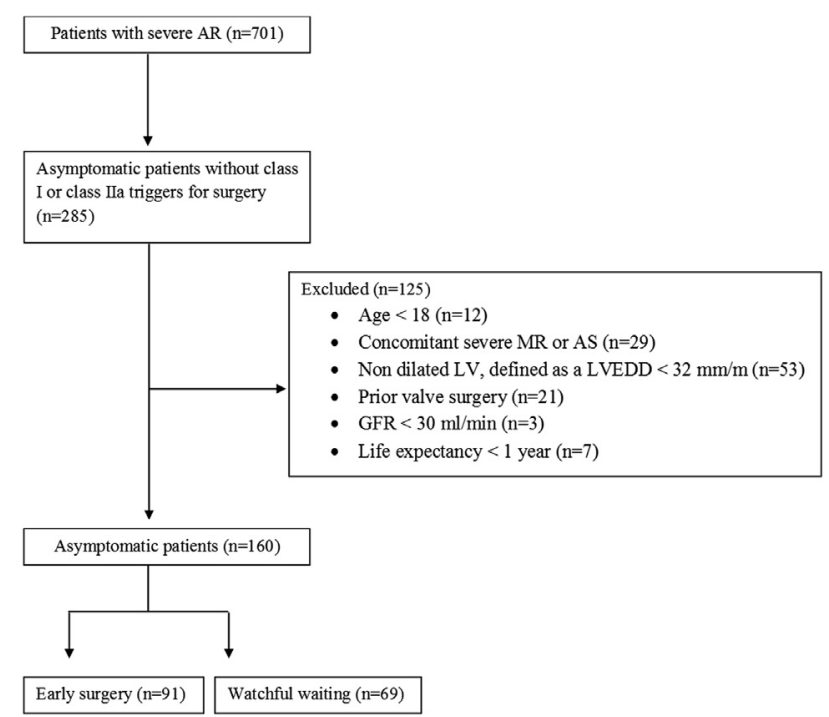

FIGURE 1. Flow chart of the study population. $A R$, Aortic regurgitation; $M R$, mitral regurgitation; $A S$, aortic stenosis; $L V$, left ventricular; $L V E D D$, left ventricular end-diastolic dimension; GFR, glomerular filtration rate.

\section{Outcome}

Information on postdiagnosis events was obtained for all patients between January and April 2014. Follow-up was 97\% complete. Five patients, living outside of Belgium, were lost for follow-up. Accordingly, they were censored at the time of last medical contact. Events and causes of death were ascertained by contacting the patients' physicians or the patients themselves, and by reviewing death certificates, coroners' reports, or autopsy records. Events were defined as AV reoperations (excluding the index operation in both groups) and cardiovascular death.

\section{Statistical Analysis}

All statistical analyses were performed using SPSS 20.0 software (IBM Inc, Chicago, Ill) and the $\mathrm{R}$ software version 3.0.1. Continuous variables were expressed as mean \pm 1 standard deviation, categoric variables were expressed as counts and percentages, and follow-up times were expressed as median and range. Groups were compared by use of the Student $t$ test or chi-square tests when appropriate.

Overall survival was computed using the Kaplan-Meier method and compared using the log-rank chi-square test. For each patient included in the study, the corresponding average age- and gender-specific annual mortality rates of the Belgian general population were obtained. On the basis of these mortality data, the probability of cumulative expected survival was determined and an expected survival curve was constructed. Determination of the factors independently associated with outcome was performed by use of a Cox proportional-hazards survival analysis. For this purpose, all clinical, angiographic, and echocardiographic variables with a $P$ value less than .10 in the univariate analysis were proposed for inclusion in a multivariate Cox proportional-hazards survival model. Variable selection was performed using an interactive stepwise selection procedure using the maximum partial likelihood ratio chi-square statistic (chi-square test) to enter $(<.05$ level $)$ or to remove $(>.05$ level $)$ a covariate into the model. Variables were entered until no F-to-enter statistics were significant at the $5 \%$ level and until the mean squared error reached a minimum.

Propensity score matching. Variables that were associated with survival as indicated in univariate Cox proportional hazard regression models were used for calculating propensity scores. The propensity for early surgery was then estimated using a logistic regression model with the response variable being early surgery (yes/no). The 9 covariables used to build the propensity were age, gender, body surface area, bicuspid $\mathrm{AV}$, type I dysfunction, type III dysfunction, systolic blood pressure, diastolic blood pressure, and LV diastolic diameter. A single propensity score was generated for each patient. The calculated propensity scores were then used to select pairs of patients with matched propensity scores in the 2 groups (1:1 match) within a caliper of 0.19 standard deviations of the propensity score, using the STATA 10.0 software (StataCorp LP, College Station, Tex) and the psmatch routine.

Inverse probability weighting. Using the same baseline characteristics for the propensity score calculation allowed case-weight estimation with a logistic regression model to predict the inverse probability of undergoing early surgery. The case weights balanced the cohorts for an inverse probability-weighted (IPW) analysis that included all patients with available data. Weighted $t$ tests and weighted chi-square tests were used in the IPW-adjusted cohort to compare continuous or categoric variables in the 2 groups. Standardized differences were calculated to compare baseline characteristics in the 2 groups for the original and the IPW-adjusted cohort. ${ }^{19}$ Cox proportional hazard regression models were adjusted for inverse probability weights ${ }^{20,21}$ to determine the impact of the treatment strategy on survival. The proportional hazards assumption in the Cox models was assessed with Schoenfeld residuals; the model fit was evaluated with martingale and Cox-Snell residuals.

Finally, to evaluate the risk ratio to develop 1 guideline criteria during the follow-up in the conservatively managed patients, the time between each visit (where echocardiographic and symptoms were assessed by the practitioner) was introduced in a mixed effects Poisson regression model to account for the longitudinal design of our study.

\section{RESULTS \\ Baseline Characteristics}

The clinical, hemodynamic, and echocardiographic characteristics of the 160 patients who met the inclusion criteria are shown in Tables 1 and 2. Patients were separated into 2 groups according to the initial treatment strategy. The 69 patients who were initially managed conservatively were included in the "conservatively managed" group, and the remaining 91 patients, who underwent operation within the first 3 months after diagnosis, were included in the "early surgery" group.

In the "early surgery" group, surgery consisted of AVsparing surgery in 76 patients, a Ross procedure in 7 patients, and an AVR in the remaining 8 patients ( 2 mechanical and 6 bioprosthetic replacements). In the conservatively managed group, class I or class IIa triggers developed in 32 patients during follow-up (dilatation of the ascending aorta in 2, symptoms in $8, \mathrm{LV}$ dysfunction in 3 , and LV dilatation $>70 \mathrm{~mm}$ in 19). Each of them was offered surgery; 29 patients accepted and eventually underwent operation (AVsparing surgery in 21 , bioprosthetic valve replacement in 7, and Ross procedure in 1), and 3 refused and continued to be managed conservatively.

\section{Overall and Cardiovascular Survivals}

During a median follow-up of 7.2 years (range, 0.1-18.6), 14 patients died, 7 in the early surgery group ( 2 postoperative deaths, 1 aortic aneurysm rupture, and 4 noncardiac deaths) and 7 in the conservatively managed group ( 3 cardiac deaths and 4 noncardiac deaths). 
TABLE 1. Baseline clinical characteristics of 160 asymptomatic patients with severe aortic regurgitation

\begin{tabular}{|c|c|c|c|c|c|c|c|c|c|c|}
\hline \multirow[b]{3}{*}{$\begin{array}{c}\text { Characteristic, } \\
\%\end{array}$} & \multirow{3}{*}{$\begin{array}{c}\text { Total } \\
(\mathrm{n}=\mathbf{1 6 0}) \\
\begin{array}{c}\text { Mean } \pm 1 \\
\text { SD }\end{array}\end{array}$} & \multicolumn{3}{|c|}{ Overall population } & \multicolumn{3}{|c|}{$\begin{array}{c}\text { Propensity score-matched } \\
\text { cohort (1:1) }\end{array}$} & \multicolumn{3}{|c|}{$\begin{array}{c}\text { Inverse probability-weighted } \\
\text { cohort }\end{array}$} \\
\hline & & $\begin{array}{c}\text { Conservative } \\
(\mathrm{n}=69) \\
\end{array}$ & $\begin{array}{c}\text { Early } \\
\text { surgery } \\
(\mathbf{n}=91) \\
\end{array}$ & & $\begin{array}{c}\text { Conservative } \\
(n=46) \\
\end{array}$ & $\begin{array}{c}\text { Early } \\
\text { surgery } \\
(n=46) \\
\end{array}$ & & $\begin{array}{c}\text { Conservative } \\
(\mathrm{n}=69)\end{array}$ & $\begin{array}{c}\text { Early } \\
\text { surgery } \\
(\mathbf{n}=91) \\
\end{array}$ & \\
\hline & & $\begin{array}{c}\text { Mean } \pm 1 \\
\text { SD }\end{array}$ & $\begin{array}{c}\text { Mean } \pm 1 \\
\text { SD }\end{array}$ & $\begin{array}{c}P \\
\text { value }\end{array}$ & $\begin{array}{l}\text { Mean } \pm 1 \\
\text { SD }\end{array}$ & $\begin{array}{l}\text { Mean } \pm 1 \\
\text { SD }\end{array}$ & $\begin{array}{c}P \\
\text { value }\end{array}$ & $\begin{array}{l}\text { Mean } \pm 1 \\
\text { SD }\end{array}$ & $\begin{array}{c}\text { Mean } \pm 1 \\
\text { SD }\end{array}$ & $\begin{array}{c}P \\
\text { value }\end{array}$ \\
\hline \multicolumn{11}{|l|}{ Demographics } \\
\hline Age (y) & $50 \pm 17$ & $50 \pm 18$ & $49 \pm 16$ & .72 & $51 \pm 19$ & $50 \pm 16$ & .61 & $51 \pm 19$ & $50 \pm 16$ & .81 \\
\hline Male gender (n, \%) & $132(83)$ & $53(77)$ & $79(87)$ & .10 & $38(83)$ & $39(85)$ & .78 & $81 \%$ & $80 \%$ & .96 \\
\hline $\operatorname{BSA}\left(\mathrm{m}^{2}\right)$ & $1.9 \pm 0.2$ & $1.9 \pm 0.2$ & $2.0 \pm 0.2$ & .002 & $1.9 \pm 0.2$ & $1.9 \pm 0.2$ & .97 & $1.9 \pm 0.2$ & $1.9 \pm 0.2$ & .59 \\
\hline \multicolumn{11}{|l|}{ History/comorbidities } \\
\hline PCI/CABG $(n, \%)$ & $4(3)$ & $4(6)$ & $0(0)$ & - & $3(7)$ & $0(0)$ & - & $5 \%$ & $0 \%$ & - \\
\hline Stroke $(\mathrm{n}, \%)$ & $5(3)$ & $2(3)$ & $3(3)$ & .89 & $2(4)$ & $2(4)$ & $>.99$ & $2 \%$ & $3 \%$ & .72 \\
\hline $\operatorname{PAD}(\mathrm{n}, \%)$ & $1(1)$ & $1(1)$ & $0(0)$ & - & $1(2)$ & $0(0)$ & - & $1 \%$ & $0 \%$ & - \\
\hline COPD (n, \%) & $4(3)$ & $1(1)$ & $3(3)$ & .46 & $0(0)$ & $1(2)$ & - & $1 \%$ & $2 \%$ & .65 \\
\hline $\begin{array}{l}\text { Atrial fibrillation } \\
\quad(\mathrm{n}, \%)\end{array}$ & $16(10)$ & $8(12)$ & $8(9)$ & .56 & $7(15)$ & $3(7)$ & .18 & $8 \%$ & $6 \%$ & .60 \\
\hline $\begin{array}{r}\text { GFR Cockcroft } \\
\left(\mathrm{mL} / \mathrm{min} / \mathrm{m}^{2}\right)\end{array}$ & $108 \pm 36$ & $101 \pm 35$ & $113 \pm 36$ & .054 & $101 \pm 39$ & $104 \pm 33$ & .64 & $103 \pm 37$ & $106 \pm 36$ & .70 \\
\hline \multicolumn{11}{|l|}{ Risk factors } \\
\hline $\begin{array}{l}\text { Smoking history } \\
\quad(\mathrm{n}, \%)\end{array}$ & $39(24)$ & $17(25)$ & $22(24)$ & .95 & $8(17)$ & $12(26)$ & .32 & $16 \%$ & $23 \%$ & .27 \\
\hline $\begin{array}{l}\text { Hypertension } \\
\quad(\mathrm{n}, \%)\end{array}$ & $65(41)$ & $25(36)$ & $40(44)$ & .33 & $15(33)$ & $18(39)$ & .89 & $34 \%$ & $47 \%$ & .12 \\
\hline $\begin{array}{l}\text { Diabetes mellitus } \\
\quad(\mathrm{n}, \%)\end{array}$ & $7(4)$ & $4(6)$ & $3(3)$ & .45 & $3(7)$ & $3(7)$ & $>.99$ & $7 \%$ & $13 \%$ & .20 \\
\hline $\begin{array}{l}\text { Dyslipidemia } \\
\text { (n, \%) }\end{array}$ & $16(10)$ & $4(6)$ & $12(13)$ & .12 & $1(2)$ & $6(13)$ & .05 & $5 \%$ & $19 \%$ & .012 \\
\hline $\begin{array}{l}\text { Family history } \\
\text { of } \operatorname{CAD}(n, \%)\end{array}$ & $21(13)$ & $7(10)$ & $14(15)$ & .33 & $5(11)$ & $8(17)$ & .38 & $8 \%$ & $14 \%$ & .23 \\
\hline \multicolumn{11}{|l|}{ Aortic pathology } \\
\hline Marfan (n, \%) & $4(3)$ & $2(3)$ & $2(2)$ & .78 & $2(4)$ & $0(0)$ & - & $4 \%$ & $1 \%$ & .28 \\
\hline Bicuspid AV (n, \%) & $81(51)$ & $30(43)$ & $51(56)$ & .12 & $21(46)$ & $24(52)$ & .54 & $46 \%$ & $48 \%$ & .85 \\
\hline Type I AR (n, \%) & $40(25)$ & $11(16)$ & $29(32)$ & .02 & $10(22)$ & $8(17)$ & .60 & $31 \%$ & $31 \%$ & .99 \\
\hline Type II AR (n, \%) & $74(46)$ & $37(54)$ & $37(41)$ & .10 & $21(46)$ & $22(48)$ & .84 & $42 \%$ & $41 \%$ & .88 \\
\hline Type III AR (n, \%) & $46(29)$ & $21(30)$ & $25(27)$ & .68 & $15(33)$ & $16(35)$ & .83 & $26 \%$ & $28 \%$ & .86 \\
\hline
\end{tabular}

$S D$, Standard deviation; $B S A$, body surface area; $P C I$, percutaneous coronary intervention; $C A B G$, coronary artery bypass grafting; $P A D$, peripheral artery disease; $C O P D$, chronic obstructive pulmonary disease; GFR, glomerular filtration rate; $C A D$, coronary artery disease; $A V$, aortic valve; $A R$, aortic regurgitation.

As shown in Figure 2, $A$ and Table 3, overall and cardiovascular survivals were similar among the unmatched early surgery and the conservatively managed groups. Similar results were obtained in the propensity scorematched (Figure 2, B) and the IPW-adjusted (Figure 2, $C$ ) cohorts.

Multivariate Cox proportional hazards analysis identified age $(P=.003$; hazard ratio $[\mathrm{HR}], 1.08$; 95\% confidence interval $[\mathrm{CI}], 1.03-1.13)$ and male gender ( $P=.024$, HR, 0.26; 95\% CI, 0.08-0.84) as independent predictors of survival in the unmatched population. Early surgical management was not a predictor of overall survival $(P=.45)$. To estimate the propensity scoreadjusted HR associated with early surgery, the propensity score was entered with the early surgical management into a bivariate Cox proportional hazards analysis. In this analysis as well, early surgical management was not found to be a predictor of overall survival $(P=.72)$. Finally, in Cox models adjusted for IPW, early surgical management also was not a predictor of overall survival $(P=.66)$.

\section{Subgroup Analyses}

Specific subgroup analyses were conducted in patients with repairable valves (AR type I and II), ${ }^{18}$ in patients with bicuspid valves, and in patients without class IIb indication for surgery according to the latest AHA/ACC guidelines (asymptomatic patients with severe AR, normal resting $\mathrm{LV}$ systolic function and $\mathrm{LV}$ end-diastolic diameter $>65 \mathrm{~mm}$, and low surgical risk). 
TABLE 2. Baseline hemodynamic and echocardiographic characteristics of 160 patients with severe aortic regurgitation

\begin{tabular}{|c|c|c|c|c|c|c|c|c|c|c|}
\hline \multirow[b]{3}{*}{ Characteristic, $\%$} & \multirow{3}{*}{$\begin{array}{c}\text { Total } \\
(n=160) \\
\begin{array}{c}\text { Mean } \pm 1 \\
\text { SD }\end{array}\end{array}$} & \multicolumn{3}{|c|}{ Overall population } & \multicolumn{3}{|c|}{$\begin{array}{c}\text { Propensity score-matched } \\
\text { cohort }(1: 1) \\
\end{array}$} & \multicolumn{3}{|c|}{$\begin{array}{c}\text { Inverse probability-weighted } \\
\text { cohort } \\
\end{array}$} \\
\hline & & $\begin{array}{c}\text { Conservative } \\
(\mathbf{n}=69) \\
\end{array}$ & $\begin{array}{c}\text { Early } \\
\text { surgery } \\
(\mathrm{n}=91) \\
\end{array}$ & & $\begin{array}{c}\text { Conservative } \\
(n=46) \\
\end{array}$ & 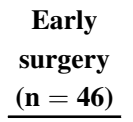 & & $\begin{array}{c}\text { Conservative } \\
(\mathbf{n}=69) \\
\end{array}$ & $\begin{array}{c}\text { Early } \\
\text { surgery } \\
(\mathbf{n}=91) \\
\end{array}$ & \\
\hline & & $\begin{array}{c}\text { Mean } \pm 1 \\
\text { SD }\end{array}$ & $\begin{array}{c}\text { Mean } \pm 1 \\
\text { SD }\end{array}$ & $\begin{array}{c}P \\
\text { value }\end{array}$ & $\begin{array}{c}\text { Mean } \pm 1 \\
\text { SD }\end{array}$ & $\begin{array}{c}\text { Mean } \pm 1 \\
\text { SD }\end{array}$ & $\begin{array}{c}P \\
\text { value }\end{array}$ & $\begin{array}{c}\text { Mean } \pm 1 \\
\text { SD }\end{array}$ & $\begin{array}{c}\text { Mean } \pm 1 \\
\text { SD }\end{array}$ & $\begin{array}{c}P \\
\text { value }\end{array}$ \\
\hline \multicolumn{11}{|l|}{ Hemodynamic data } \\
\hline Systolic BP (mm Hg) & $139 \pm 18$ & $143 \pm 18$ & $136 \pm 17$ & .014 & $140 \pm 18$ & $137 \pm 17$ & .37 & $140 \pm 17$ & $140 \pm 21$ & .82 \\
\hline Diastolic BP (mm Hg) & $69 \pm 12$ & $74 \pm 12$ & $66 \pm 12$ & $<.001$ & $70 \pm 12$ & $69 \pm 13$ & .64 & $72 \pm 11$ & $71 \pm 15$ & .83 \\
\hline Heart rate (beats/min) & $68 \pm 11$ & $68 \pm 11$ & $68 \pm 11$ & .89 & $68 \pm 11$ & $70 \pm 12$ & .39 & $67 \pm 11$ & $68 \pm 11$ & .89 \\
\hline \multicolumn{11}{|l|}{ Echocardiographic data } \\
\hline LVDd (mm) & $62 \pm 5$ & $61 \pm 5$ & $63 \pm 4$ & $<.001$ & $61 \pm 4$ & $62 \pm 4$ & .29 & $62 \pm 5$ & $62 \pm 4$ & $>.99$ \\
\hline $\operatorname{LVSd}(\mathrm{mm})$ & $41 \pm 5$ & $40 \pm 5$ & $43 \pm 4$ & $<.001$ & $40 \pm 5$ & $42 \pm 4$ & .096 & $40 \pm 5$ & $41 \pm 5$ & .22 \\
\hline Ejection fraction $(\%)$ & $59 \pm 6$ & $58 \pm 6$ & $59 \pm 6$ & .44 & $59 \pm 6$ & $60 \pm 6$ & .47 & $59 \pm 6$ & $58 \pm 6$ & .28 \\
\hline
\end{tabular}

$S D$, Standard deviation; $B P$, blood pressure; $L V D d$, left ventricular diastolic diameter; $L V S d$, left ventricular systolic diameter.

In patients with repairable valves, both overall and cardiovascular survivals were found to be similar among the early surgery and conservatively managed groups (Table 3 ). Similar findings were observed in patients with bicuspid valves and the subgroup of 114 patients without a class IIb trigger.

\section{Need for Repeat Surgery and Postoperative Deaths}

During follow-up, there were 12 events in the early surgery group (9 repeat operations, all in patients who underwent sparing surgery, and 3 cardiovascular deaths) and 4 events in the conservatively managed group ( 2 postoperative cardiac deaths and 2 repeat operations). As shown in Figure 3, cardiovascular event-free survival tended to be better in the conservatively managed group than in the early surgery group.

In the conservatively managed group, class I or class IIa triggers for surgery developed in 32 patients. A mixed model for repeated measures was used to determine the risk ratio to develop operative triggers. The linearized risk to develop class I or IIa triggers for surgery was $9.9 \%$ / 10 years. It was $7.4 \% / 10$ years for $\mathrm{LV}$ dilatation, $0.6 \% /$ 10 years for symptoms, $0.9 \% / 10$ years for $\mathrm{LV}$ dysfunction, and $0.3 \% / 10$ years for dilatation of the ascending aorta.

\section{Effect of Follow-up Regularity in the Conservatively Managed Group}

To evaluate the potential influence of the regularity and quality follow-up visits on outcome, patients in the conservatively managed group were further subdivided into a watchful waiting subgroup consisting of 49 patients who were seen by a registered cardiologist at least once a year and an irregular follow-up subgroup consisting of 20 patients who were not. Among the 49 patients in the watchful waiting subgroup, operative triggers developed in 31 and surgery was offered; 2 of them refused. By contrast, none of the patients in the irregular follow-up subgroup underwent AV surgery. As shown in
Figure 4, patients in the watchful waiting subgroup had a significantly better 10 -year overall survival than patients undergoing no or a looser follow-up $(100 \%$ vs $90 \%$ at 5 years and $95 \%$ vs $79 \%$ at 10 years, $P=.045)$.

\section{DISCUSSION}

As in severe mitral regurgitation, the optimal timing for surgery in asymptomatic patients with severe $\mathrm{AR}$ is a matter of intense debate. Although current AHA/ACC and ESC guidelines recommend delaying surgery until the appearance of symptoms, LV dysfunction, or severe LV dilatation, some have advocated intervening earlier to prevent the development of irreversible LV dysfunction and the persistence of heart failure symptoms after successful AVR. ${ }^{16,22}$ In an attempt to solve this controversy, we compared these 2 treatment strategies, that is, an early surgical approach, before the onset of class I or class IIa operative triggers, and a conservative approach, in which patients are referred to surgery only after the onset the same triggers. The data indicate that these 2 approaches result in similar long-term survival, as long as conservatively managed patients are closely followed up and referred to surgery as soon as class I or IIa operative triggers develop. In the absence of regular follow-up, the appropriate time window for intervention is likely to be missed, resulting in an increased overall mortality risk. Our results thus suggest that it is safe to delay AR surgery until the onset of class I or IIa triggers and that current recommendations for AR surgery are appropriate.

\section{Natural History of Severe Aortic Regurgitation in Asymptomatic Patients}

Several previous studies have investigated the natural history of severe AR. ${ }^{1,5,22}$ They demonstrated that long-term prognosis in patients with severe AR was mostly determined by the presence of symptoms and LV systolic dysfunction. Although on average these studies have shown 
Overall population

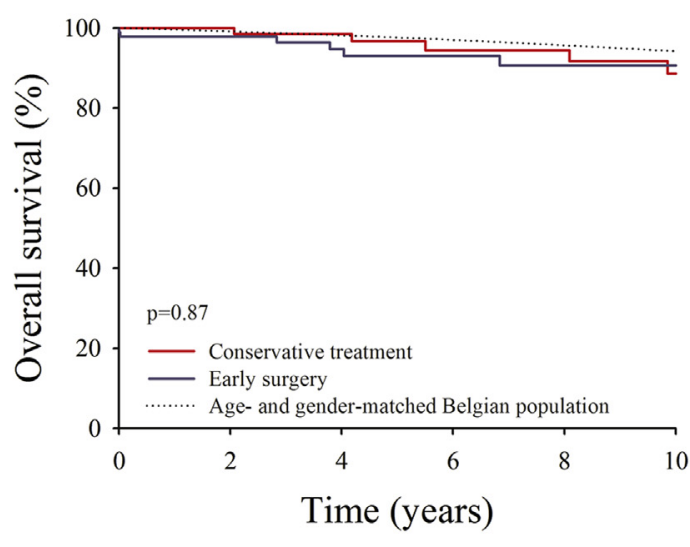

Matched Cohorts

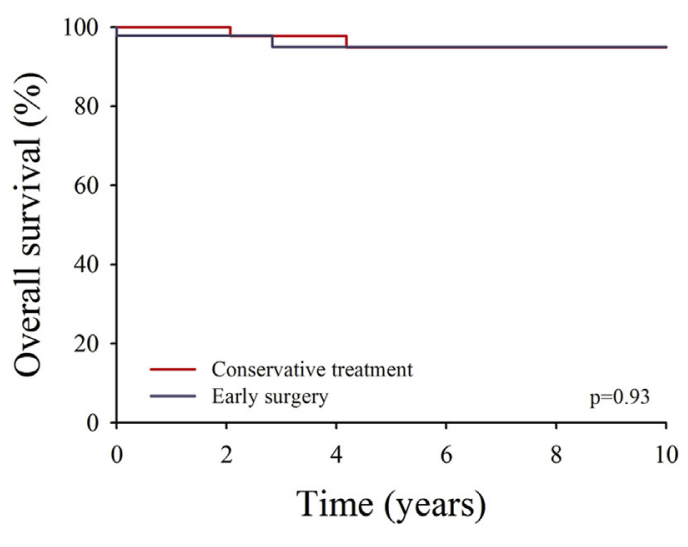

$\begin{array}{lllllll}\text { Conservative treatment } & 69 & 67 & 54 & 40 & 34 & 29 \\ \text { A Early surgery } & 91 & 78 & 56 & 42 & 36 & 25\end{array}$

B Early surgery

44

$\begin{array}{llll}35 & 26 & 22 & 20 \\ 32 & 23 & 19 & 14\end{array}$

IPW-adjusted cohorts

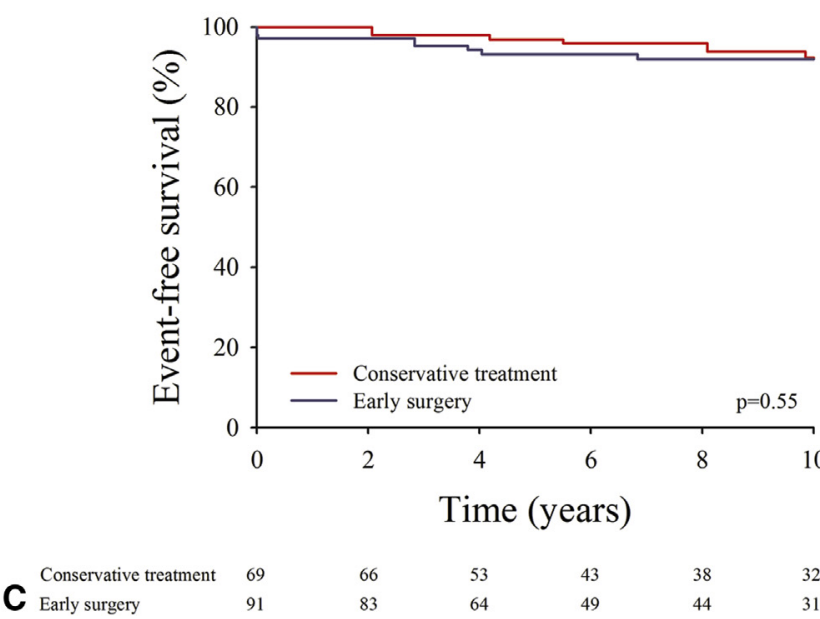

FIGURE 2. Kaplan-Meier survival curves comparing 10-year overall postoperative survival in patients undergoing early surgery (blue line) or initial medical management (red line). Survival in the overall population (A), propensity score-matched cohorts (B), and IPW-adjusted cohorts (C). Numbers at bottom indicate patients at risk. IPW, Inverse probability-weighted.

that in the absence of surgical correction, initially asymptomatic patients with severe AR with a normal LV systolic function incurred a $20 \%$ to $25 \%$ 10-year overall mortality risk, a value that is larger than in an age- and gendermatched population, they also have shown that the risk of dying before the onset of symptoms or LV dysfunction was low, on the order of $0.2 \%$ per year. The progression to symptoms or LV dysfunction is equally low, being less than $6 \%$ per year. By contrast, when symptoms or LV dysfunction have developed, the mortality risks markedly increase, exceeding $10 \%$ per year.

The present study confirms these previous findings. Indeed, in our conservatively managed patients, 10-year survival in the absence of surgery was $83 \%$. Our data also show that the likelihood for initially asymptomatic patients with severe AR to develop operative triggers is low, the likelihood of developing severe LV dilatation, becoming symptomatic or developing LV dysfunction being only $7.4 \%, 0.6 \%$ and $0.9 \%$ per 10 years, respectively. Globally, the adverse event rate in our patients was $9.9 \%$ per 10 years, a figure that is lower than that reported by Bonow and colleagues more than 20 years ago. Differences in both the severity of AR and the patients' medical management likely explain these outcome differences; most of Bonow and colleagues' patients were diagnosed between 1973 and 1988, at a time when quantitative Doppler echocardiographic assessment of AR was not available. ${ }^{1}$ 


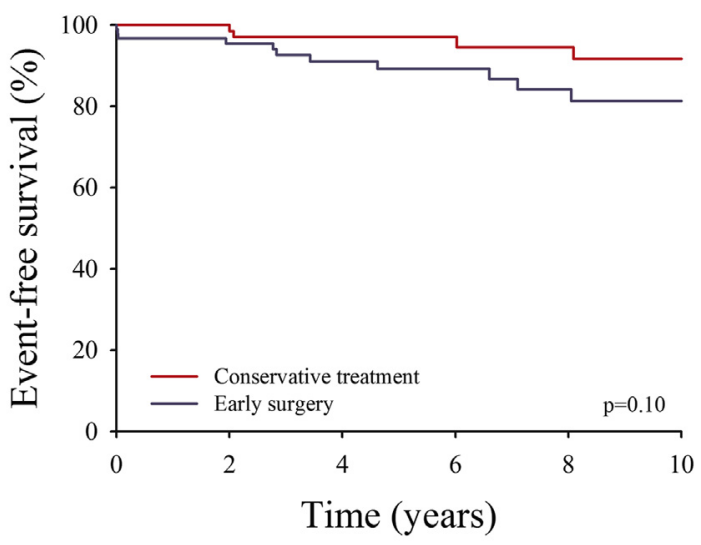

$\begin{array}{lllllll}\text { Conservative treatment } & 69 & 67 & 53 & 39 & 33 & 28\end{array}$

$\begin{array}{llllll}\text { Early surgery } & 91 & 76 & 53 & 38 & 30\end{array}$

FIGURE 3. Kaplan-Meier survival curves comparing major cardiovascular events in initially asymptomatic patients with severe AR between those undergoing early surgery (blue line) and those managed conservatively (red line).

\section{Outcome With Surgery}

Almost all postoperative studies published so far concur on the negative impact of severe preoperative symptoms (NYHA class III/IV) or LV dysfunction on postoperative outcomes. ${ }^{7-9}$ Yet, none of these studies ever demonstrated any significant postoperative survival differences between patients in NYHA class I and patients in NYHA class II, at least in the absence of LV dysfunction or severe LV dilatation. Accordingly, both the AHA/ACC and the ESC guidelines consider that, in patients in NYHA class I, it is safe to delay surgery until the development of NYHA class II symptoms, provided that LV function remains normal and the LV is not overly dilated. Although recommended in the guidelines, this strategy has never really been tested in daily clinical practice. To the best of our knowledge, the present study thus represents the first attempt to demonstrate its appropriateness. As mentioned earlier, despite our liberal use of $\mathrm{AV}$-sparing techniques, which have been shown to reduce operative risks and improve long-term outcomes, ${ }^{13,15}$ our data failed to indicate any significant differences in long-term survival between patients who underwent operation early, before the onset of class I or IIa operative triggers, and those who were followed up conservatively and underwent operation as soon as these triggers had developed, which suggests that current recommendations are appropriate. Our results are nonetheless at variance with those reported in patients with asymptomatic mitral regurgitation (MR), in whom most studies have shown a survival advantage of an early surgical correction compared with a watchful waiting approach. We believe these differences reflect the more dismal nature of severe MR compared with severe AR. Previous studies have indeed indicated that overall survival in initially asymptomatic unoperated patients with severe MR was rather low. For instance, in the study of Montant and colleagues, ${ }^{23}$ - and 10 -year overall survivals in these patients were only $63 \%$ and $24 \%$, respectively, whereas in the study by Enriquez-Sarano and colleagues, ${ }^{24} 5$-year survival was $58 \%$. In comparison, the spontaneous outcome of conservatively managed patients in NYHA class 1 with severe AR is more benign. In the present study, their 10-year overall survival was $83 \%$, whereas it was $75 \%$ in the study by Dujardin and colleagues. ${ }^{5}$ Of note, in both valvular regurgitations, the outcome after early valve repair surgery is similar in patients with NYHA class I, operative mortality being less than $1 \%$ and long-term outcome being equal to that of an age- and gender-matched population.

\section{Study Limitations}

First, despite the completeness of our follow-up data and the prospective nature of the database from which the data were retrieved, the patients were not randomized between conservative and early surgery managements. Therefore, we cannot exclude the possibility that unaccounted confounding factors contributed to our results. Second, AV repair is a demanding procedure that is currently performed

TABLE 3. Five- and 10-year Kaplan-Meier survivals

\begin{tabular}{|c|c|c|c|c|c|}
\hline & \multicolumn{2}{|c|}{ Early surgery } & \multicolumn{2}{|c|}{ Conservatively managed group } & \multirow[b]{2}{*}{$\begin{array}{c}\text { Log-rank } \\
P \text { value } \\
\end{array}$} \\
\hline & $\begin{array}{c}\text { 5-y survival } \\
(95 \% \mathrm{CI})\end{array}$ & $\begin{array}{c}\text { 10-y survival } \\
(95 \% \text { CI })\end{array}$ & $\begin{array}{c}\text { 5-y survival } \\
(\mathbf{9 5} \% \mathrm{CI})\end{array}$ & $\begin{array}{c}\text { 10-y survival } \\
(95 \% \mathrm{CI})\end{array}$ & \\
\hline \multicolumn{6}{|l|}{ Overall survival } \\
\hline Unmatched cohort & $93 \%(84-97)$ & $91 \%(80-96)$ & $97 \%(87-99)$ & $89 \%(74-95)$ & .87 \\
\hline Propensity score-matched cohort & $95 \%(81-99)$ & $95 \%(81-99)$ & $95 \%(81-99)$ & $95 \%(81-99)$ & .93 \\
\hline IPW-adjusted cohort & $93 \%(88-99)$ & $92 \%(86-98)$ & $97 \%(93-100)$ & $92 \%(85-100)$ & .55 \\
\hline \multicolumn{6}{|l|}{ Overall survival in subgroups } \\
\hline AR type I or II & $94 \%(82-98)$ & $91 \%(76-97)$ & $98 \%(86-100)$ & $85 \%(64-94)$ & .84 \\
\hline Bicuspid AVs & $100 \%(100-100)$ & $100 \%(100-100)$ & $100 \%(100-100)$ & $92 \%(57-99)$ & .27 \\
\hline No class IIb triggers & $91 \%(78-97)$ & $91 \%(78-97)$ & $98 \%(84-100)$ & $90 \%(72-97)$ & .69 \\
\hline Cardiovascular survival & $96 \%(89-99)$ & $96 \%(89-99)$ & $99 \%(90-99)$ & $96 \%(82-99)$ & .79 \\
\hline Event-free survival & $89 \%(79-95)$ & $81 \%(68-90)$ & $97 \%(89-99)$ & $92 \%(78-97)$ & .10 \\
\hline
\end{tabular}

$C I$, Confidence interval; $I P W$, inverse probability-weighted; $A R$, aortic regurgitation; $A V$, aortic valve. 


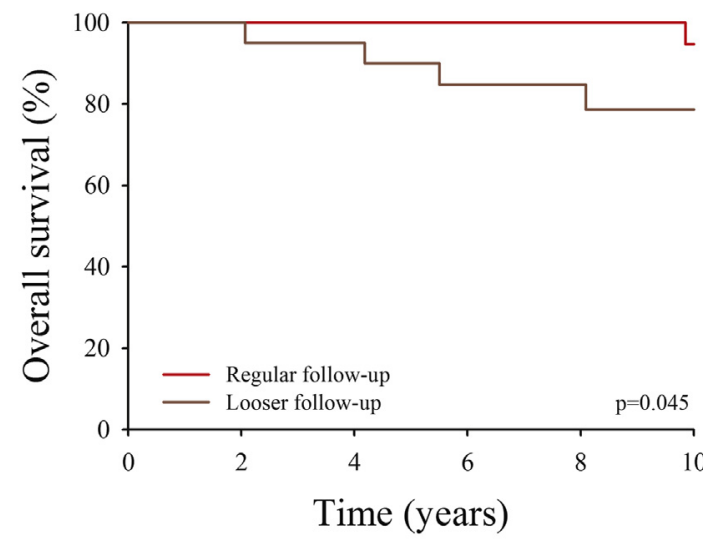

$\begin{array}{lllllll}\text { Regular follow-up } & 49 & 47 & 35 & 24 & 20 & 18\end{array}$

FIGURE 4. Kaplan-Meier survival curves comparing overall mortality in initially asymptomatic patients with severe AR managed conservatively, according to the regularity and quality of follow-up (yearly regular follow-up [red line], looser follow-up [brown line $]$ ).

in few high-volume and highly specialized centers. Despite the low operative mortality of this new technique, it requires special skills and experience. One should thus exercise caution when translating our results to smaller or lessexperienced centers without preliminary special training. Third, we used a semiquantitative multiparametric approach to assess AR severity. Although this integrated approach is the one recommended by both the ASE and the European Association for Echocardiography, the absence of quantitative measures of AR severity, such as the regurgitant volume, the effective regurgitant orifice area, or both, could be viewed as a possible limitation. To address this issue, we analyzed separately the outcome of patients diagnosed before and after we started to systematically acquire quantitative parameters of AR severity in our echocardiographic laboratory, that is, in 2006. Although the follow-up is shorter for the period 2006 to 2010, survivals in the early surgery and conservatively managed groups were found to be similar between the periods 1995 and 2005 and 2006 and 2010 (data not shown). Fourth, it would have been interesting to investigate possible differences in the recovery of LV function or changes in functional capacity between the early surgery and the conservatively managed groups, because this could affect patient quality of life and survival. Unfortunately, data on LV function were not systematically captured in our databases because many patients were followed up at another institution. However, data of functional status are available and show no differences between the 2 groups (data not shown). Finally, we arbitrarily selected 3 months for dividing the group into early surgery and conservatively managed as the window for performance of early surgical intervention based on clinical observation of the practicalities of patients making arrangements to schedule and undergo AV surgery. Even with early surgery defined as occurring within 1 or 6 months after diagnosis in exploratory models, early surgical intervention was not associated with better outcomes than initial medical management (at 1 month: adjusted HR, 0.90; 95\% CI, 0.31-2.59; $P=.84$; at 6 months: adjusted HR, 0.86; 95\% CI, 0.30-2.47; $P=.78$ ).

\section{CONCLUSIONS}

Our results show that the survival of asymptomatic patients with severe AR is not different between an early surgical strategy and a more conservative strategy, provided that the conservatively managed patients are regularly followed up and referred to surgery as soon as operative triggers develop.

\section{Conflict of Interest Statement}

Authors have nothing to disclose with regard to commercial support.

The authors thank Annie Robert, $\mathrm{PhD}$, for providing thoughtful statistical review and advice.

\section{References}

1. Bonow RO, Carabello BA, Chatterjee K, de Leon AC Jr, Faxon DP, Freed MD, et al. Serial long-term assessment of the natural history of asymptomatic patients with chronic aortic regurgitation and normal left ventricular systolic function. Circulation. 1991;84:1625-35.

2. Nishimura RA, Otto CM, Bonow RO, Carabello BA, Erwin JP, Guyton RA, et al 2014 AHA/ACC Guideline for the Management of Patients With Valvular Heart Disease: A Report of the American College of Cardiology/American Heart Association Task Force on Practice Guidelines. J Am Coll Cardiol. 2014;63: e57-185.

3. Vahanian A, Baumgartner H, Bax J, Butchart E, Dion R, Filippatos G, et al. The Joint Task Force on the Management of Valvular Heart Disease of the European Society of Cardiology (ESC) and the European Association for Cardio-Thoracic Surgery (EACTS). Eur J Cardiothorac Surg. 2012;42:S1-44.

4. Siemienczuk D, Greenberg B, Morris C, Massie B, Wilson RA, Topic N, et al. Chronic aortic insufficiency: factors associated with progression to aortic valve replacement. Ann Intern Med. 1989;110:587-92.

5. Dujardin KS, Enriquez-Sarano M, Schaff HV, Bailey KR, Seward JB, Tajik AJ. Mortality and morbidity of aortic regurgitation in clinical practice. A long-term follow-up study. Circulation. 1999;99:1851-7.

6. Klodas E, Enriquez-Sarano M, Tajik AJ, Mullany CJ, Bailey KR, Seward JB Optimizing timing of surgical correction in patients with severe aortic regurgitation: role of symptoms. J Am Coll Cardiol. 1997;30:746-52.

7. Chaliki HP, Mohty D, Avierinos JF, Scott CG, Schaff HV, Tajik AJ, et al. Outcomes after aortic valve replacement in patients with severe aortic regurgitation and markedly reduced left ventricular function. Circulation. 2002;106:2687-93.

8. Tornos P, Sambola A, Permanyer-Miralda G, Evangelista A, Gomez Z, SolerSoler J. Long-term outcome of surgically treated aortic regurgitation: influence of guideline adherence toward early surgery. J Am Coll Cardiol. 2006;47:1012-7.

9. Tamas E, Broqvist M, Olsson E, Franzen S, Nylander E. Exercise radionuclide ventriculography for predicting post-operative left ventricular function in chronic aortic regurgitation. JACC Cardiovasc Imaging. 2009;2:48-55.

10. Borer JS, Hochreiter C, Herrold EM, Supino P, Aschermann M, Wencker D, et al Prediction of indications for valve replacement among asymptomatic or minimally symptomatic patients with chronic aortic regurgitation and normal left ventricular performance. Circulation. 1998;97:525-34.

11. Klodas E, Enriquez-Sarano M, Tajik AJ, Mullany CJ, Bailey KR, Seward JB. Aortic regurgitation complicated by extreme left ventricular dilation: longterm outcome after surgical correction. J Am Coll Cardiol. 1996;27:670-7.

12. Bonow RO, Picone AL, McIntosh CL, Jones M, Rosing DR, Maron BJ, et al. Survival and functional results after valve replacement for aortic regurgitation from 
1976 to 1983: impact of preoperative left ventricular function. Circulation. 1985; 72:1244-56.

13. Boodhwani M, de Kerchove L, Glineur D, Poncelet A, Rubay J, Astarci P, et al. Repair-oriented classification of aortic insufficiency: impact on surgical techniques and clinical outcomes. J Thorac Cardiovasc Surg. 2009; 137:286-94.

14. de Kerchove L, Boodhwani M, Glineur D, Vandyck M, Vanoverschelde JL, Noirhomme P, et al. Valve sparing-root replacement with the reimplantation technique to increase the durability of bicuspid aortic valve repair. J Thorac Cardiovasc Surg. 2011;142:1430-8.

15. de Meester C, Pasquet A, Gerber BL, Vancraeynest D, Noirhomme P, El Khoury G, et al. Valve repair improves the outcome of surgery for chronic severe aortic regurgitation: a propensity score analysis. J Thorac Cardiovasc Surg. 2014;148:1913-20

16. Sharma V, Suri RM, Dearani JA, Burkhart HM, Park SJ, Joyce LD, et al. Expanding relevance of aortic valve repair-is earlier operation indicated? J Thorac Cardiovasc Surg. 2014;147:100-7.

17. Zoghbi WA, Enriquez-Sarano M, Foster E, Grayburn PA, Kraft CD, Levine RA, et al. Recommendations for evaluation of the severity of native valvular regurgitation with two-dimensional and Doppler echocardiography. J Am Soc Echocardiogr. 2003;16:777-802.

18. le Polain de Waroux JB, Pouleur AC, Goffinet C, Vancraeynest D, Van Dyck M, Robert A, et al. Functional anatomy of aortic regurgitation: accuracy, prediction of surgical repairability, and outcome implications of transesophageal echocardiography. Circulation. 2007;116:I264-9.
19. Austin PC. Balance diagnostics for comparing the distribution of baseline covariates between treatment groups in propensity-score matched samples. Stat Med. 2009;28:3083-107.

20. Hernán MA, Brumback B, Robins JM. Marginal structural models to estimate the joint causal effect of non randomized treatments. J Am Stat Assoc. 2001;96: 440-8.

21. Robins JM, Hernán MA, Brumback B. Marginal structural models and causal inference in epidemiology. Epidemiology. 2000;11:550-60.

22. Detaint D, Messika-Zeitoun D, Maalouf J, Tribouilloy C, Mahoney DW, Tajik AJ, et al. Quantitative echocardiographic determinants of clinical outcome in asymptomatic patients with aortic regurgitation: a prospective study. JACC Cardiovasc Imaging. 2008;1:1-11.

23. Montant P, Chenot F, Robert A, Vancraeynest D, Pasquet A, Gerber BL, et al. Long-term survival in asymptomatic patients with severe degenerative mitral regurgitation. A propensity score based comparison between an "early surgical" and a "conservative" treatment approach. J Thorac Cardiovasc Surg. 2009;138: 1339-48.

24. Enriquez-Sarano M, Avierinos JF, Messika-Zeitoun D, Detaint D, Capps M, Nkomo V, et al. Quantitative determinants of the outcome of asymptomatic mitral regurgitation. N Engl J Med. 2005;352:875-83.

Key Words: aortic regurgitation, aortic valve repair, early surgery

\title{
EDITORIAL COMMENTARY
}

\section{Gospel of the guidelines}

\author{
Leora B. Balsam, MD, and Abe DeAnda, Jr, MD
}

From the Department of Cardiothoracic Surgery, New York University-Langone Medical Center, New York, NY. Disclosures: Authors have nothing to disclose with regard to commercial support.

Received for publication Aug 12, 2015; accepted for publication Aug 13, 2015; available ahead of print Sept 10, 2015.

Address for reprints: Leora B. Balsam, MD, Department of Cardiothoracic Surgery, New York UniversityLangone Medical Center, 530 First Ave, Suite 9V, New York, NY 10016 (E-mail: leora.balsam@nyumc.org). J Thorac Cardiovasc Surg 2015;150:1108-10 0022-5223/\$36.00

Copyright (c) 2015 by The American Association for Thoracic Surgery http://dx.doi.org/10.1016/j.jtcvs.2015.08.047

Consensus statements are the modern method of summarizing best-evidence guidelines in the practice of medicine. They are a framework that synthesizes the existing literature into bullet points of do's and don'ts that are based on specific levels of evidence. One perspective is that clinical practice guidelines are a set of rules to follow, and that these rules maintain order in the management of common diseases. After all, medicine is a science, and as such, certain methods and treatments have been validated (or disproved) through observational studies and clinical trials. The committees tasked with creating guidelines comb through the literature and put together a summation based on critical and exhaustive review of primary data, and their conclusions can be far-reaching in the practice of medicine.

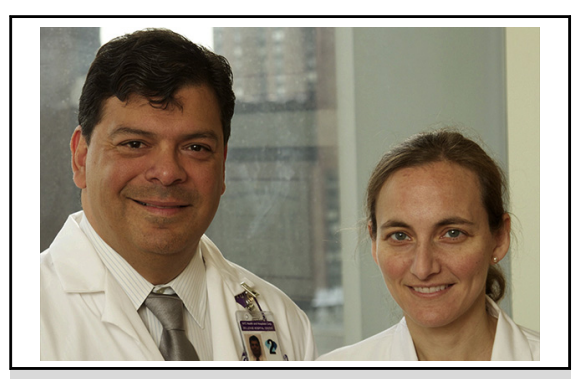

Abe DeAnda, Jr, MD, and Leora B. Balsam, MD

Central Message

In the era of evidence-based medicine, there remains a need for research and innovation, even in areas where guidelines exist.

See Article page 1100

A different perspective is that guidelines fail to capture nuances of individual cases, leaving the practitioner to decide how to balance patient-specific needs with population-based solutions. Finally, guidelines can stifle creativity and innovation, and for surgeons in particular, 